\title{
Thermal Effect on Characteristics of IZTO Thin Films Deposited by Pulsed DC Magnetron Sputtering
}

\author{
Dong Jin Son, Yoon Duk Ko, ${ }^{\dagger}$ Dong Geun Jung, Jin Hyo Boo, ${ }^{\ddagger}, *$ Sung Hoon Choa, ${ }^{\S}$ and Young Sung Kim ${ }^{\S}, *$ \\ Department of Physics, Institute of Basic Science, and Brain Korea 21 Physics Research Division, \\ Sungkyunkwan University, Suwon 440-746, Korea \\ ${ }^{\dagger}$ Display Lab, Sungkyunkwan University, Suwon 440-746, Korea \\ ¿Department of Chemistry, Institute of Basic Science, Sungkyunkwan University, Suwon 440-746, Korea \\ ${ }^{*}$ E-mail:jhboo@skku.edu \\ ${ }^{\S}$ Graduate School of NID Fusion Technology, Seoul National University of Science and Technology, Seoul 139-743, Korea \\ EE-mail: youngsk@seoultech.ac.kr \\ Received December 9, 2010, Accepted December 30, 2010
}

\begin{abstract}
This study examined In-Zn-Sn-O (IZTO) films deposited on glass substrates by pulsed DC magnetron sputtering with various substrate temperatures. The structural, electrical, optical properties were analyzed. Xray diffraction showed that the IZTO films prepared at temperatures $>150{ }^{\circ} \mathrm{C}$ were crystalline which adversely affected the electrical properties. Amorphous IZTO films prepared at $100{ }^{\circ} \mathrm{C}$ showed the best properties, such as a low resistivity, high transmittance, figure of merit, and high work function of $4.07 \times 10^{-4} \Omega, 85 \%$, $10.57 \times 10^{-3} \Omega^{-1}$, and $5.37 \mathrm{eV}$, respectively. This suggests that amorphous IZTO films deposited at relatively low substrate temperatures $\left(100{ }^{\circ} \mathrm{C}\right)$ are suitable for electrode applications, such as OLEDs as a substitute for conventional crystallized ITO films.
\end{abstract}

Key Words : TCO (transparent conducting oxide), IZTO (indium zinc tin oxide), Substrate temperature, Pulsed dc magnetron sputter

\section{Introduction}

The use of transparent conducting oxides (TCOs) has increased remarkably with the growth of mobile devices, such as electrode applications for various flat panel displays (FPDs) and touch screen panels (TSPs). ${ }^{1}$ In particular, polycrystalline tin-doped $\mathrm{In}_{2} \mathrm{O}_{3}$ (ITO) is commonly used for many opto-electronic applications owing to its good electrical and optical properties, such as low resistivity and high transmittance in the visible light region. ${ }^{2}$ Nevertheless, that the applications of polycrystalline ITO films are limited by the low work function, high deposition temperature and rough surface. ${ }^{3}$ For this reason, amorphous ITO and In-Zn-O (IZO) electrodes have been studied as potential substitutes for conventional ITO films. However, the electrical and optical properties of amorphous ITO films do not satisfy the requirements for applications to flexible optoelectronic devices. ${ }^{4}$ Amorphous $\mathrm{Zn}$-doped $\mathrm{In}_{2} \mathrm{O}_{3}$ films also have some limitations as TCO electrodes because the manufacture of sintered IZO targets is complicated and costly. ${ }^{5}$ Recently, In-Zn-Sn-O (IZTO) has attracted considerable attention as a new amorphous TCO material to resolve the abovementioned problems owing to its high work function, low resistivity, high transparency, and low deposition temperature. ${ }^{6,7}$ However, the electrical, and structural properties with chemical binding analysis of IZTO films have not been investigated in detail. In this sudy, IZTO films were deposited on glass substrates by DC magnetron sputtering at different substrate temperatures. The structural, electrical, and optical properties of the IZTO films were investigated. The interrelation between the chemical binding state of the surface and the characteristics of IZTO films was analyzed by X-ray photoelectron spectroscopy (XPS). The work function of the IZTO films was measured to evaluate the possibility of alternative TCO applications such as OLEDs.

\section{Experiment}

$200 \mathrm{~nm}$-thick IZTO thin films with various substrate temperatures were deposited on Corning 1737 glass substrates by pulsed DC magnetron sputtering with a sintered IZTO ceramic target $\left(\mathrm{In}_{2} \mathrm{O}_{3} 80 \mathrm{wt} \%, \mathrm{ZnO} 10 \mathrm{wt} \%, \mathrm{SnO}_{2} 10\right.$ wt \%). The plasma power and working pressure was 6.17 $\mathrm{W} / \mathrm{cm}^{2}$ and $6 \mathrm{mTorr}$, respectively. The substrate temperature was varied from room temperature to $200{ }^{\circ} \mathrm{C}$. X-ray diffraction (XRD) was performed to examine the structure properties of the IZTO films. The surface morphology was analyzed by filed emission scanning electron microscopy (FESEM). The resistivity, carrier density and mobility of the IZTO thin films were measured using the van der Pauw method with a Hall measurement system. X-ray photoelectron spectroscopy (XPS) was used to confirm the surface chemical state of the IZTO films. The transmittance was investigated in the wavelength range, $200-1100 \mathrm{~nm}$, using a UV-visible spectrometer. The work function on the IZTO films was measured by ultraviolet photoemission spectroscopy. 


\section{Results and Discussion}

XRD was used to investigate the structural properties of the IZTO films deposited by pulsed DC magnetron sputtering. Figure 1 shows the XRD pattern of the IZTO films grown on glass substrates as a function of the substrate temperature. The XRD plots of IZTO films in temperature range from RT to $100{ }^{\circ} \mathrm{C}$ showed weak and broad peaks, indicating an amorphous IZTO structure $\left(2 \theta=\sim 31^{\circ}\right)$. On the other hand, increasing the substrate temperature to $200{ }^{\circ} \mathrm{C}$ caused the crystallization of IZTO films. The crystallization of ITO films occurs rapidly at low substrate temperatures due to low amorphous/crystalline transition temperature $\left(\leq 150{ }^{\circ} \mathrm{C}\right) .{ }^{6}$ In our study, the IZTO films deposited above $150{ }^{\circ} \mathrm{C}$ showed a sharp peak at $30.58^{\circ} 2 \theta$ with a broad

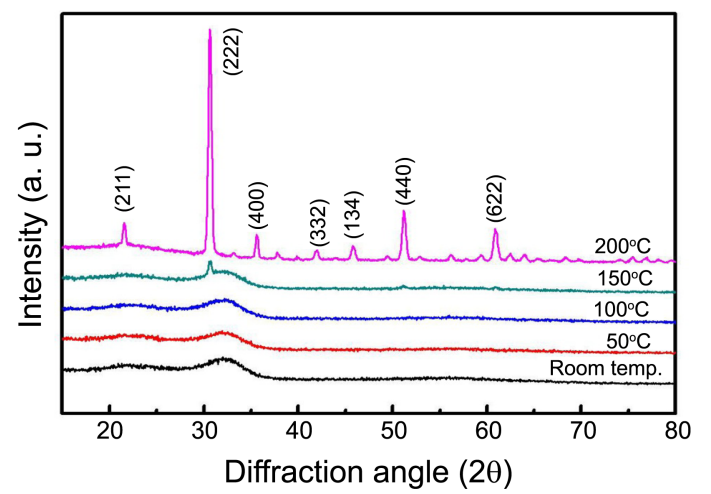

Figure 1. X-ray diffraction patterns of the IZTO thin films prepared with different substrate temperatures.

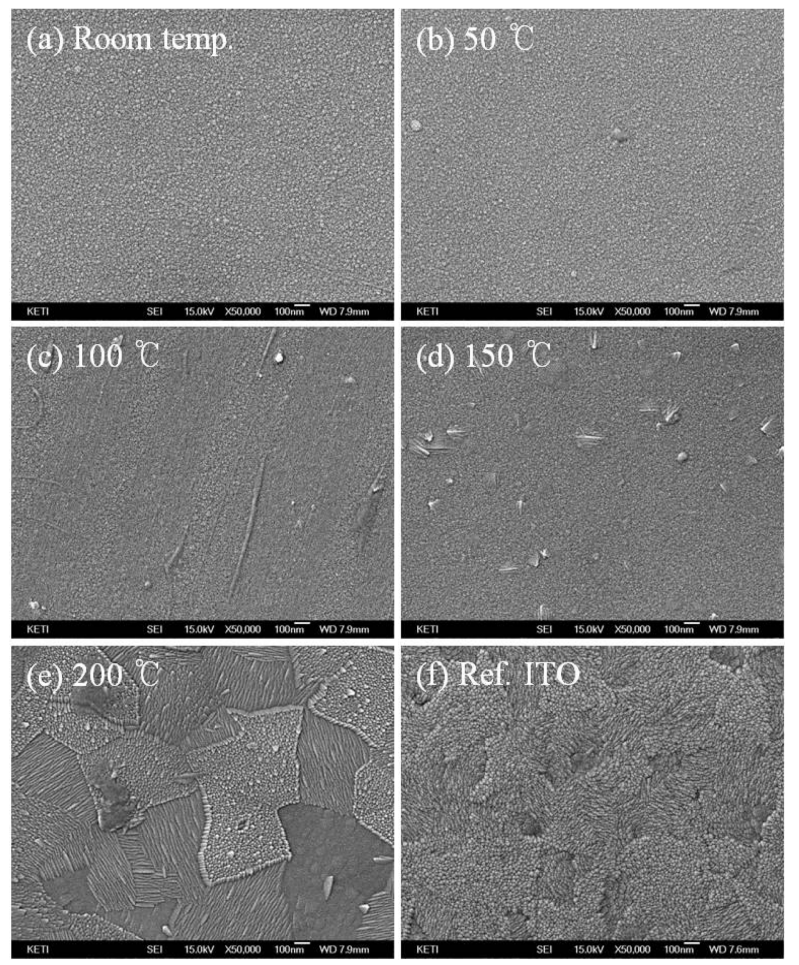

Figure 2. Surface FESEM images of the IZTO films grown on glass substrates at (a) Room temperature, (b) $50{ }^{\circ} \mathrm{C}$ (c) $100{ }^{\circ} \mathrm{C}$ (d) $150{ }^{\circ} \mathrm{C}$ (e) $200{ }^{\circ} \mathrm{C}$ (f) Ref. ITO. amorphous IZTO peak. In addition, the XRD patterns of the $200{ }^{\circ} \mathrm{C}$ showed several peaks indicative of a crystalline structure, even though $\mathrm{ZnO}$ doped $\mathrm{In}_{2} \mathrm{O}_{3}$ has a high amorphous/crystalline transition temperature.

Figure 2 shows FESEM images of the commercial reference ITO film and the IZTO films prepared on glass substrates with different substrate temperature. Only the film deposited at $200{ }^{\circ} \mathrm{C}$ had poly-crystallized domain grains with a finely oriented columnar structure of sub grains.

It is also notable that the film deposited at $150{ }^{\circ} \mathrm{C}$ shows a partially crystallized surface morphology, which corresponds to the XRD diffraction results. However, the IZTO films grown at relatively low temperatures $\left(\leq 100{ }^{\circ} \mathrm{C}\right)$ showed a very smooth and featureless surface without defects owing its amorphous structure. A smooth surface is very important for IZTO films for applications as an anode layer of OLEDs or flexible displays because anode spikes can cause the breakdown or shorting of the inter-layers in devices. ${ }^{8}$

Figure 3 shows the resistivity, carrier concentration and Hall mobility of IZTO films as a function of substrate temperature with the other deposition conditions kept constant. The resistivity of the IZTO film decreased with increasing substrate temperature until $150{ }^{\circ} \mathrm{C}$ but increased rapidly with further increases in substrate temperature. To understand the change in resistivity in Figure 3, the origins of electrical charge carrier concentration and Hall mobility should be considered. A free electron acting as a carrier in Sn doped $\mathrm{In}_{2} \mathrm{O}_{3}$ is caused by two types of donors: a native defect such as oxygen vacancies and a $\mathrm{Sn}^{4+}$ ion substituting for $\mathrm{In}^{3+}{ }^{9,10}$ In the case of a low deposition temperature from RT to $100{ }^{\circ} \mathrm{C}$, oxygen vacancies due to a change in stoichiometry would contribute as an electrical charge carrier. Furthermore, the creation of free electrons from singly charged $\mathrm{Sn}_{\text {In }}$ is another source for the increase in charge concentration in the IZTO films. As the substrate temperature increases from RT to $100{ }^{\circ} \mathrm{C}$, the electronic charge concentration would increase but the decrease in Hall mobility would compensate for the resistivity due to the increasing scattering centers. Therefore, the electrical resis-

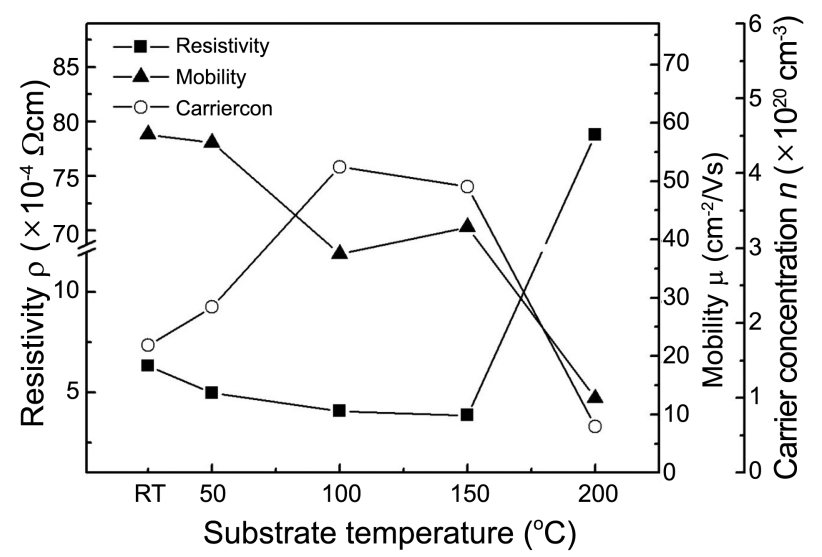

Figure 3. Resistivity ( $\rho)$, carrier concentration (n), and Hall mobility $(\mu)$ of IZTO films prepared by pulsed DC magnetron sputtering as function of the substrate temperature. 

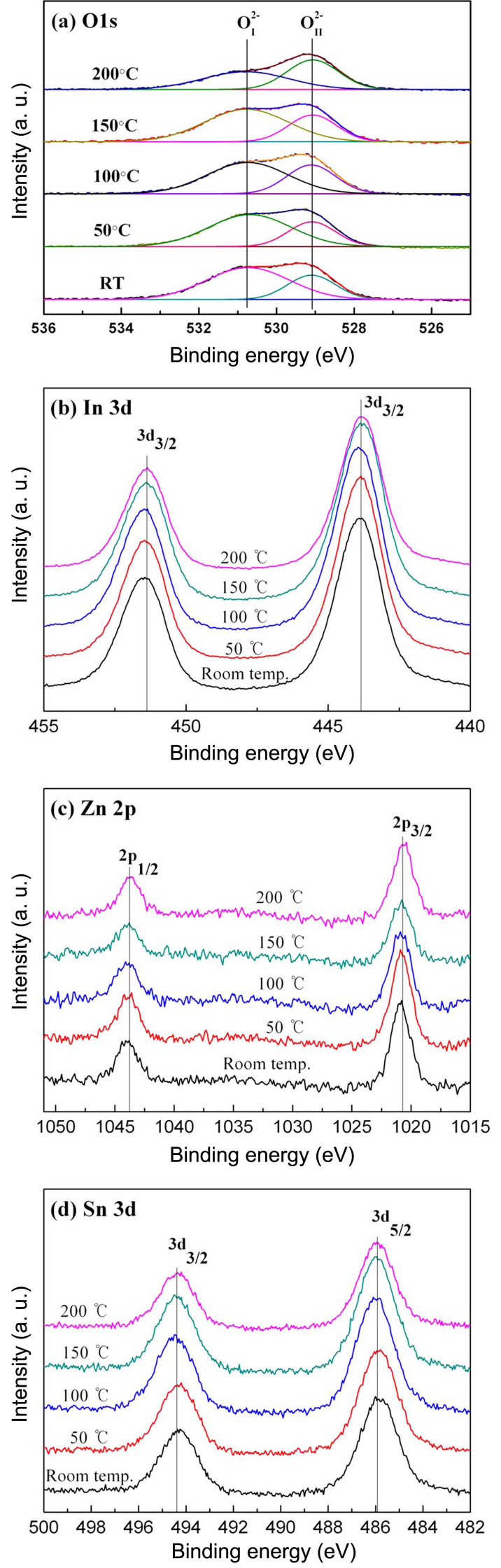

Figure 4. XPS core level spectra of (a) O 1s, (b) In 3d, (c) Zn 2p, (d) Sn 3d obtained for IZTO films grown on a glass substrate as a function of the substrate temperature.

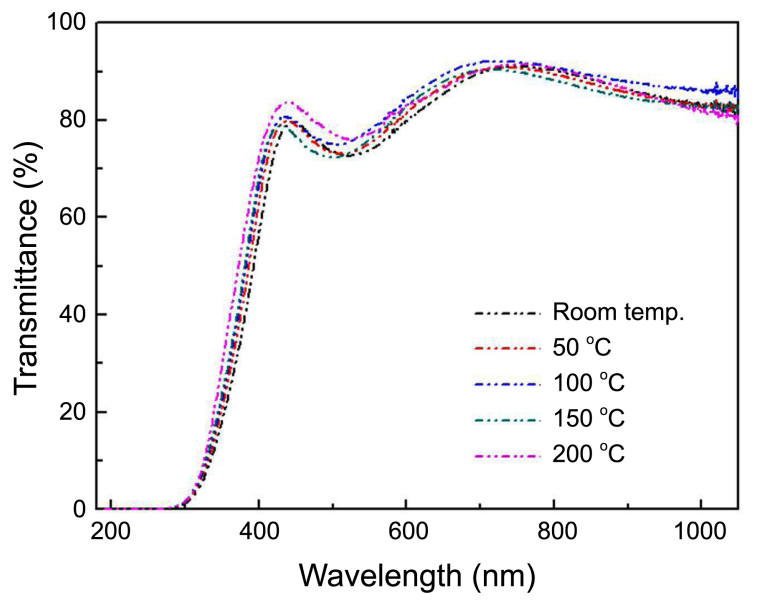

Figure 5. Optical transmission spectra of IZTO thin films grown by pulsed DC magnetron sputtering as a function of the substrate temperature.

tivity would decrease slightly with increasing substrate temperature up to $150{ }^{\circ} \mathrm{C}$. However, a further increase in substrate temperature leads to a decrease in the carrier concentration of IZTO films; the carrier compensation due to doped $\mathrm{Zn}$ acting as an acceptor may reduce the carrier concentration because of substitution of $\mathrm{Zn}^{2+}$ ion in a $\mathrm{In}^{3+}$ site can occur at high temperatures. ${ }^{11}$ In particular, the crystallization of IZTO films at $200{ }^{\circ} \mathrm{C}$ decreases the mobility rapidly. A noticeable decrease in carrier mobility was also observed in the crystallized IZTO film deposited at $200{ }^{\circ} \mathrm{C}$ because grain boundary formation in the crystalline films formed an additional scattering barrier for electrons. ${ }^{12}$ Therefore, the electrical resistivity increases drastically with increasing substrate temperature at $200{ }^{\circ} \mathrm{C}$.

The chemical binding state of the IZTO films was examined by XPS analysis as a function of the substrate temperature. Figure 4 shows the XP core level spectra for $\mathrm{O}$ 1s, In 3d, Zn 2p, and Sn 3d on from the surface of the IZTO films. As the substrate temperature is increased, no obvious change in the In 3d, Zn 2p, and Sn 3d peaks was observed. However the higher binding peak in the $\mathrm{O} 1$ s peak obtained from the IZTO film deposited at $200{ }^{\circ} \mathrm{C}$ was lower than that obtained from the IZTO film deposited at RT- $150{ }^{\circ} \mathrm{C}$, as shown in Figure 4(a). John et al. reported two types of $\mathrm{O}^{2-}$ ions : a lower binding energy peak $\left(\mathrm{O}_{\text {III }}\right)$ from $\mathrm{O}^{2-}$ ions with neighboring In atoms with their full complement; and a higher binding energy peak $\left(\mathrm{O}_{\mathrm{I}}\right)$ corresponding to oxygendeficient regions. ${ }^{13}$ In the present study, the binding energy ratio $\left(\mathrm{I}\left(\mathrm{O}_{\mathrm{I}}\right) / \mathrm{I}\left(\mathrm{O}_{\mathrm{II}}\right)\right)$ of the IZTO films at room temperature, $50,100,150$ and $200^{\circ} \mathrm{C}$ was $1.90,1.92,2.09,1.90$ and 0.86 , respectively. Therefore, the intensity in the higher binding peaks in the $\mathrm{O}$ 1s peak suggests that the concentration of oxygen vacancies increases with increasing substrate temperature from RT to $100^{\circ} \mathrm{C}$. On the other hand, from $200^{\circ} \mathrm{C}$, the intensity of the higher binding energy peak decreased rapidly because the number of oxygen vacancies decreased with increasing substrate temperature. This suggests that the electrical carrier density of the IZTO films is related sensitively 


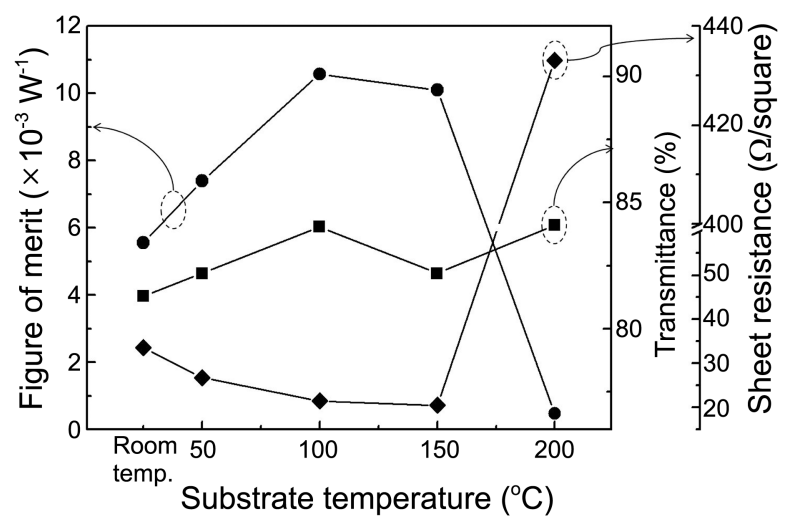

Figure 6. Figure of merit, average transmittance, and sheet resistance of the IZTO thin films as a function of the substrate temperature.

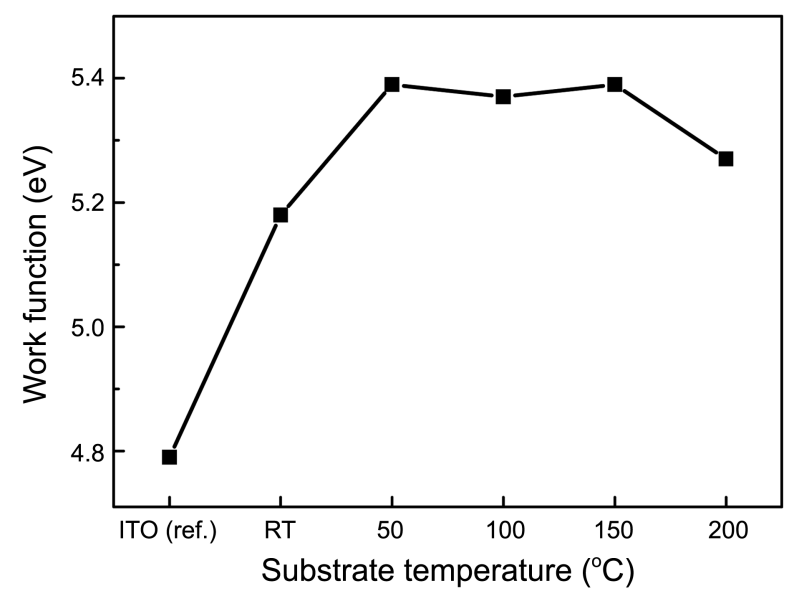

Figure 7. Work function of the IZTO thin films deposited at different substrate temperatures.

to the binding energy ratio $\left(\mathrm{I}\left(\mathrm{O}_{\mathrm{I}}\right) / \mathrm{I}\left(\mathrm{O}_{\mathrm{II}}\right)\right)$. Moreover, the tendency of the binding energy ratio is consistent with the electrical properties as shown in Figure 3.

Figure 5 shows the optical transmittance spectra of the IZTO layer as a function of the substrate temperature. The average transmittance of all IZTO films was $\geq 80 \%$ in the visible light region (400-800 $\mathrm{nm}$ ) and no clear difference in transmittance was observed between the films. This means that the transmittance of the IZTO films deposited at low substrate temperatures $\left(\leq 100{ }^{\circ} \mathrm{C}\right)$ is comparable to that deposited at high substrate temperatures. In particular, the IZTO film grown at $100{ }^{\circ} \mathrm{C}$, exhibited approximately $85 \%$ transmittance, which is similar to conventional ITO films.

Figure 6 shows the figure of merit, mean optical transmittance, and sheet resistance of the IZTO films as a function of the substrate temperature. The figure of merit $\left(\Phi_{\mathrm{TC}}\right)$, which was suggested by Haacke, was calculated from the equation below using the average transmittance $(\mathrm{T})$ and sheet resistance $\left(\mathrm{R}_{\text {sheet }}\right){ }^{13}$ The $\Phi_{\mathrm{TC}}$ can provide information for comparing the performance of TCO films with similar optical transmittance and electrical resistivity. The increase in substrate temperature leads to an increase in the $\Phi_{\mathrm{TC}}$ value of IZTO films with high transmittance and low resistivity.
However, for substrate temperatures $\geq 150^{\circ} \mathrm{C}$, the $\Phi_{\mathrm{TC}}$ value decreases due to the low transmittance $\left(\right.$ at $150{ }^{\circ} \mathrm{C}$ ) or high $\mathrm{R}_{\text {sheet }}\left(\right.$ at $200{ }^{\circ} \mathrm{C}$ ) of the IZTO films. From the evaluated $\Phi_{\mathrm{TC}}$ value of the IZTO films, it was decided that the optimum substrate temperature for IZTO films is $100{ }^{\circ} \mathrm{C}$.

Figure 7 shows the work functions of the IZTO films. The measured work functions for the IZTO film at room temperature, $50,100,150$ and $200{ }^{\circ} \mathrm{C}$ were $5.18,5.39,5.37$, 5.39 and $5.27 \mathrm{eV}$, respectively, which were higher than that of the reference ITO film $(4.8 \mathrm{eV})$. Most significantly, the work functions of IZTO films were $\geq 5.0 \mathrm{eV}$, i.e., closer to the typical values for highest occupied molecular orbital (HOMO) in organic electroluminescent semiconductors. This means that IZTO films are more advantageous than ITO for electrode applications requiring a lower hole injection barrier into the organic layer HOMO levels.

\section{Conclusions}

This study examined the effect of the substrate temperature from RT to $200{ }^{\circ} \mathrm{C}$ on the structural, electrical, and optical properties of IZTO films deposited by pulsed DC magnetron sputtering. The crystallization of IZTO films was affected mainly by the substrate temperature. In addition, the electrical properties of the IZTO films, such as carrier density and Hall mobility, were influenced sensitively by the level of crystallinity. Under optimized conditions, the amorphous IZTO films showed a resistivity, optical transmittance, figure of merit and work function of $4.07 \times 10^{-4}$ $\Omega \cdot \mathrm{cm}, 85 \%, 10.57 \times 10^{-3} \Omega^{-1}$, and $5.37 \mathrm{eV}$, respectively, even though it had been prepared at a low substrate temperature of $100{ }^{\circ} \mathrm{C}$. However, the properties of the IZTO films above $200{ }^{\circ} \mathrm{C}$ were degraded due to crystallization. This indicates that an amorphous structure is advantageous to IZTO films because amorphous IZTO films show comparable electrical and optical properties to crystalline IZTO films.

Acknowledgments. Support of this research by the National Research Foundation of Korea (Grant No: 20100025481) is gratefully acknowledged. This work was also supported by the Energy Efficiency \& Resources Recycling of the Korea Institute of Energy Technology Evaluation and Planning (KETEP) grant funded by the Korea government Ministry of Knowledge Economy.

\section{References}

1. Coutts, T. J.; Young, D. L. MRS Bulletin 2000, 8, 58.

2. Kim, H.; Piqué, A.; Horwitz, J. S. Appl. Phys. Lett. 1999, 74, 3444.

3. Shen, Y.; Jacobs, D. B.; Malliaras, G. G.; Koley, G.; Spencer, M. G.; Ioannidis, A. Adv. Mater. 2001, 13, 1234.

4. Kim, D. H.; Park, M. R.; Lee, H. J.; Lee, G. H. Appl. Surf. Sci. 2006, 253, 409.

5. Liu, D. S.; Lin, C. H.; Huang, B. W.; Wu, C. C. Jpn. J. Appl. Phys. 2006, 45, 3526 .

6. Bae, J. H.; Moon, J. H.; Jeong, S. W.; Kim, J. J.; Kang, J. W.; Kim, D. G.; Kim, J. K.; Park, J. W.; Kim, H. K. J. Electrochem. Soc. 
2008, 155, J1.

7. Ow-Yang, C. W.; Yeom, H.; Paine, D. C. Thin Solid Films 2008, 516,3105 .

8. Hung, L. S.; Chen, C. H. Mater. Sci. Eng. 2002, 39, 143.

9. Frank, G.; Kowtlin, H. Appl. Phys. A 1982, 27, 197.

10. Bel Hadj Tahar, R.; Ban, T.; Ohya, Y.; Takahashi, Y. J. Appl. Phys.
1998, 83, 2631.

11. Jung, Y. S.; Seo, J. Y.; Lee, D. W.; Jeon, D. Y. Thin Solid Films 2003, $445,63$.

12. Fan, J. C. C.; Goodenough, J. B. J. Appl. Phys. 1977, 48, 3524.

13. Haacke, G. J. Appl. Phys. 1976, 47, 4086. 